\title{
GÊNERO RESENHA CRÍTICA: UMA PROPOSTA DE ENSINO DE PRODUÇÃO EM SALA DE AULA
}

\section{GENRE CRITICAL REVIEW: A PROPOSAL OF PRODUCTION TEACHING IN CLASSROOM}

\author{
Francisco Cleyton de Oliveira Paes ${ }^{1}$
}

Pollyanne Bicalho Ribeiro ${ }^{2}$

Resumo: Este artigo apresenta a análise de produções textuais de alunos do ensino fundamental, a partir da aplicação de uma sequência didática (SD) (DOLZ; NOVERRAZ; SHNEUWLY, 2004) para o ensino do gênero resenha crítica. Como arcabouço teórico, recorremos à perspectiva de gênero discursivo de Bakhtin (2003) e de Biasi-Rodrigues (2008). Em seguida, abordamos o gênero resenha crítica, por meio de Medeiros (2014) e Machado, Lousada \& Abreu-Tardelli (2014). Por fim, concluímos que, com o uso da SD, é possível que os alunos do ensino fundamental tornem-se bons escritores de textos e se apropriem dos mais diversos gêneros discursivos.

Palavras-chave: gêneros discursivos; resenha crítica; sequência didática.

Abstract: This article presents the analysis of textual productions of middle school students using the method of didactic sequence (DS) (DOLZ; NOVERRAZ; SHNEUWLY, 2004) to teach critical review. As theoretical framework, we adopt the discursive genre perspective of Bakhtin (2003) and Biasi-Rodrigues (2008). Next, we approach the critical review genre from the perspective of Medeiros (2014) and Machado, Lousada \& Abreu-Tardelli (2014). Finally, we conclude that, by using DS, it is possible for middle school students to become good text writers and appropriate the most diverse of discursive genres.

Keywords: discursive genres; critical review; didactic sequence.

\section{Introdução}

Percebe-se, com certa frequência, que os alunos do ensino básico possuem dificuldades na hora de redigir um texto e que, quando envolvidos em práticas de leitura, também têm dificuldades de analisar textos por meio de questões simples de interpretação e de compreensão textual. Os problemas relacionados ao uso da língua/linguagem podem ser percebidos nos indicadores de desempenho apresentados pelas avaliações oficiais. Em setembro de 2016, por

\footnotetext{
${ }^{1}$ Mestre em Letras pelo PROFLETRAS da Universidade Federal do Ceará, professor de Língua Portuguesa da rede pública estadual do Ceará. E-mail: cleytonpaes@gmail.com

${ }^{2}$ Doutora em Linguística Aplicada pela PUC de Minas Gerais, professora associada da Universidade Federal do Ceará. E-mail: pollyanne.bicalho@gmail.com
} 
exemplo, o governo federal divulgou o resultado da Prova Brasil 2015 ${ }^{3}$. Nessa avaliação, os resultados demonstraram que, apesar de o Estado do Ceará ter melhorado seu desempenho na prova de Língua Portuguesa, ainda se encontra no nível intermediário de desempenho.

Diante desse cenário, reconhecemos que é preciso pensar em práticas de ensino significativas, condizentes com os propósitos da Linguística Aplicada da atualidade. Nessa perspectiva, nossa pesquisa visa propor uma atividade que contempla os eixos de leitura e escrita, particularmente, para o $9^{\circ}$ ano do ensino fundamental.

A escolha dessa série deveu-se ao fato de o gênero resenha constar como componente curricular previsto para esse nível de ensino e, ainda, pela demanda de solicitações advindas de outros professores, que solicitam a produção de resenhas como atividades de apreensão do conteúdo. Vale ressaltar, ainda, que o gênero resenha é muito utilizado nas atividades acadêmicas e profissionais, assim como em todos os níveis de ensino (do ensino fundamental à universidade).

Para a constituição do Corpus, recolhemos as produções iniciais e a reescrita de resenhas que foram analisadas no âmbito da pesquisa de mestrado de Paes ${ }^{4}$. Conforme a sequência didática elaborada para esta pesquisa, houve a exibição do filme Mulher-Maravilha (2017) para as turmas de $9^{\circ}$ ano e foi solicitada uma resenha do filme como produção inicial. Em seguida, houve a proposição de dois módulos de atividades com as turmas. Não obstante o trabalho com as duas turmas, selecionamos a que teve mais adesão dos alunos na sequência didática para nossa pesquisa-ação, uma vez que, segundo Gil (2002), este tipo de pesquisa caracteriza-se pela interação entre pesquisador e membros da situação investigada.

Sabemos que é recorrente o fato de os alunos, nesta etapa escolar, estudarem apenas com foco na aprovação escolar e na sua progressão de série. Dessa forma, o principal objetivo proposto pelos PCN - formar leitores críticos e escritores autônomos -, de certa maneira, é deixado de lado. Por isso, esse artigo tem o objetivo de apresentar uma reflexão sobre o uso de gêneros discursivos nas atividades previstas para a sala de aula, aqui, particularmente, o ensino do gênero resenha crítica, como forma de propiciar contextos reais de usos pautados na vivência

\footnotetext{
${ }^{3}$ O Sistema de Avaliação da Educação Básica - Saeb, instituído em 1990, é composto por um conjunto de avaliações externas em larga escala e tem como principal objetivo realizar um diagnóstico da educação básica brasileira e de alguns fatores que possam interferir no desempenho do estudante, fornecendo um indicativo sobre a qualidade do ensino ofertado. (Disponível em:< http://portal.inep.gov.br/web/guest/educacao-basica/saeb $>$. Acesso em 08 jul 2017).

${ }^{4}$ Dissertação já defendida, mas ainda em processo de ajustes pós-defesa.
} 
de mundo dos alunos e, por conseguinte, refletir sobre as escolhas metodológicas empreendidas em sala de aula, concernentes ao ensino de Língua Portuguesa.

Nesse cenário, é notório que o ensino de Língua Portuguesa se apresenta como um desafio aos profissionais da área, uma vez que ensinar falantes da própria língua restringia-se, até pouco tempo, a ensinar apenas escrita, com foco nas regras gramaticais descontextualizadas. Porém, o ensino, conforme sugestões dos PCN e da Base Nacional Curricular Comum (BNCC), deixa a metalinguagem em segundo plano e defende a perspectiva de uso real do texto escrito ou oral, desenvolvendo competências linguísticas para o uso adequado da linguagem nas diversas situações comunicativas.

Temos consciência de que, na escola, o professor é tido como principal agente do saber e como mediador do conhecimento, pois ele é o articulador mais importante de outros agentes - como os pais, a direção da escola, por exemplo. Em vista disso, o professor deve voltar o seu fazer docente para a inserção, na rotina da turma, de atividades que contemplem práticas voltadas para o uso real de textos na sociedade.

Assim, o uso de gêneros discursivos em sala de aula não pode se efetivar de forma tradicional, ou seja, tão-somente como pretexto para leitura ou para a resolução de questões, muitas vezes, relacionadas à superfície textual. Deve haver uma compreensão calcada na inferência, valendo-se também da análise linguística para que, de fato, haja interação com o texto mobilizado.

Em vista disso, urge a transformação da sala de aula, na perspectiva de que as escolhas dos professores devem pautar o aprimoramento de práticas linguísticas cotidianas dos seus alunos. Essa tomada de posicionamento, no entanto, deve atingir não só o professor de Língua Portuguesa, mas todos os professores que lidam com gêneros diversos no cotidiano escolar.

Portanto, este artigo propõe uma ressignificação da prática formativa a partir do ensino do gênero resenha crítica e está dividido em cinco seções. Na primeira seção, há discussões a respeito dos gêneros discursivos e ensino, conforme Bakhtin (2003) e Biasi-Rodrigues (2008); na segunda, abordamos o gênero resenha crítica, de acordo com Machado, Lousada \& AbreuTardelli (2014) e Medeiros (2014); na terceira seção, apresentamos a metodologia utilizada nesta pesquisa; na quarta, a análise de dados e, por fim, as considerações finais.

\section{Gêneros discursivos na escola}


Os gêneros discursivos são instrumentos de intercomunicação nomeados socialmente, ou seja, são vistos como práticas sociais efetivas de uso da língua, como afirma Biasi-Rodrigues (2008). Daí se depreende que a língua é empregada em situações reais de comunicação, visto que nos comunicamos através de um ou outro gênero no âmbito das esferas sociais.

Segundo Bakhtin (2003), as produções textuais enunciadas em situações imediatas de comunicação são conhecidas como gêneros discursivos primários e ocorrem naturalmente na vida das pessoas ao participarem das interações. Sobre isso, Biasi Rodrigues nos afirma que

Ao adquirir a linguagem, a criança já aprende essas formas de expressão que compõem a estrutura interna dos textos e também aprende a combiná-las. Narrar ou relatar fatos, descrever objetos, pessoas e cenários, argumentar em defesa própria ou defender um ponto de vista, por exemplo, são práticas cotidianas de todos nós e das crianças antes mesmo de entrarem na escola. (BIASI RODRIGUES, 2008, p. 34)

Estas ações realizadas espontaneamente pelos indivíduos são, portanto, de pouca complexidade na sua elaboração. Já as produções mais complexas, segundo Bakhtin (2003), são classificadas como gêneros discursivos secundários. Tais práticas comunicativas surgem nas condições de um convívio cultural mais complexo e relativamente muito desenvolvido e organizado (predominantemente o escrito) - artístico, científico, sociopolítico. Assim, a produção de um gênero complexo exige que o falante desenvolva habilidades linguísticas, sendo que ele irá aprimorar o uso desses gêneros, na medida em que entende o seu funcionamento. Desse modo, é preciso interagir com esses gêneros, entender sua forma composicional, seu estilo, sua função social, sua circulação.

Entende-se que a escola é o melhor lugar onde os indivíduos podem desenvolver competências linguísticas para uma boa fruição dos gêneros discursivos mais complexos, uma vez que "ensinar o domínio da língua portuguesa é ensinar os alunos a escolher o gênero adequado a cada situação comunicativa e a usá-lo com propriedade e segurança para que surta os efeitos pretendidos nas suas experiências de vida fora da escola." (BIASI-RODRIGUES, 2008, p.46).

O domínio do gênero textual, de qualquer que seja o tipo, no entanto, não requer o ensino tão-somente das características estruturais ou das propriedades peculiares que o compõem, pois, para Bakhtin (2003), os gêneros variam em função do tema, da situação comunicativa e da composição entre os participantes. Em vista disso, percebemos que todos esses aspectos colaboram para o engendramento do gênero e devem ser contemplados na prática formativa. Nessa perspectiva, Marcuschi, ao abordar acerca do gênero, nos afirma que 
[...] não podemos defini-los mediante certas propriedades que lhe devam ser necessárias e suficientes. Assim, um gênero pode não ter uma determinada propriedade e ainda continuar sendo aquele gênero. Por exemplo, uma carta pessoal é uma carta mesmo que a autora tenha se esquecido de assinar o nome no final e só tenha dito no início: ‘querida mamãe'. (MARCHUSCHI, 2002, p. 11)

Na mesma razão, Biasi-Rodrigues acrescenta que

[...] o reconhecimento de um gênero inclui a análise do contexto de uso, ou seja, o reconhecimento de onde e quando o gênero é praticado; a identificação dos interlocutores, isto é, as intenções e propósitos do emissor e a quem pode se destinar um dado gênero; a escolha da forma mais adequada de codificar linguisticamente as informações; a análise de características textuais e linguísticas que são típicas de cada gênero. (BIASI-RODRIGUES, 2008, p. 45)

Percebe-se, dessa forma, que o contexto de produção do gênero, tanto na modalidade escrita, como na oral, é de suma importância. Esse contexto pode ser entendido como um "conjunto de parâmetros que podem exercer uma influência sobre a forma como um texto é organizado.” (BRONCKART, 2007, p.93).

A organização de um texto, de acordo com a situação social, exige do falante um certo nível de conhecimento. Esse evento propicia o desenvolvimento do indivíduo, visto que, nas interações, o sujeito se (re)constitui, se (trans)forma. Nessa perspectiva, dominar um gênero discursivo seria entender sua composição temática, seu estilo, sua construção composicional, seu contexto de uso, de produção e de circulação. Dessa forma, espera-se que o aluno consiga produzir um texto complexo de acordo com a necessidade da prática social da qual irá participar.

Vale ressaltar que a produção de um texto inscreve-se em um contexto físico relativo às "coordenadas do espaço-tempo" e "no quadro de uma forma de interação comunicativa que implica o mundo social (normas, valores, regras, etc.) e o mundo subjetivo (imagem que o agente dá de si ao agir).”. (BROCKART, 2007, p. 93-94, grifo do autor). Por isso, quanto maior for a condição de letramento ${ }^{5}$ do falante, maior será a sua capacidade de produzir textos.

Segundo Bazerman (2005), a produção de um texto bem-sucedido satisfaz a necessidade da situação comunicativa, de forma que esse gênero passa a ser compreensível e corresponde às necessidades do outro. Assim, o autor critica a identificação de gêneros por meio de características sinalizadoras, como se o gênero pudesse ser caracterizado apenas por uma

\footnotetext{
${ }^{5} \mathrm{O}$ termo letramento foi cunhado aqui como a condição do sujeito em aplicar as práticas de linguagem e as suas habilidades linguísticas nas mais diversas práticas sociais.
} 
quantidade fixa de elementos e justifica sua posição afirmando que, ao trabalhar dessa forma, estaríamos vendo os gêneros como atemporais e iguais para todos os observadores.

Concordando com esse pensamento, Bazerman nos apresenta que:

\begin{abstract}
A definição de gêneros como apenas um conjunto de traços textuais ignora o papel dos indivíduos no uso e na construção de sentidos. Ignora as diferenças de percepção e compreensão, o uso criativo da comunicação para satisfazer novas necessidades percebidas em novas circunstâncias e a mudança no modo de compreender o gênero com o decorrer do tempo. (BAZERMAN, 2005, p. 30)
\end{abstract}

Por fim, ressalta-se a importância do uso de gêneros discursivos no cotidiano da escola, visando a formação de alunos autônomos e letrados socialmente, pois, conforme Schneuwly e Dolz (2004, p.73), "as práticas de linguagem implicam tanto dimensões sociais como cognitivas e linguísticas do funcionamento da linguagem numa situação de comunicação particular.”.

\title{
2 Definição e funcionalidade do gênero resenha crítica
}

O gênero resenha é "[...] um relato minucioso das propriedades de um objeto ou de suas partes constitutivas; [...]" (MEDEIROS, 2014, p. 153). Há um tipo de resenha conhecida como resenha crítica que, segundo Silva (s/d. apud MEDEIROS, 2014), combina resumo e julgamentos de valor. Dessa forma, entende-se que, na resenha crítica, há a defesa de um ponto de vista e a apresentação de argumentos para defendê-lo. Segundo Medeiros (2014), o leitor espera um posicionamento crítico, por isso os juízos avaliativos devem ser claros e baseados em fatos ou em provas.

Na resenha crítica, além dos aspectos descritivos, o autor precisa defender um ponto de vista, por meio de argumentos. A produção desse gênero apresenta "as informações centrais sobre os conteúdos e sobre outros aspectos de outro(s) texto(s) lido(s)" no contexto produtivo e na "organização global, suas relações com outros textos etc." (MACHADO, LOUSADA; ABREU-TARDELLI, 2004, p. 14). A defesa do ponto de vista e a apreciação do autor configuram, de forma clara, o projeto de autoria do texto que, mesmo em terceira pessoa, deixase entrever a opinião do resenhista por meio dos comentários sobre os conteúdos e sobre outros aspectos do objeto.

Segundo Marcuschi (2002, p. 89), "os textos operam basicamente em contextos comunicativos". Logo, o professor precisa criar as condições reais de circulação dos textos e, por isso, tem-se na escola o lugar ideal para a produção e a utilização de textos com o objetivo de levar o aluno ao domínio do gênero (DOLZ; SCHNEUWLY, 2004). Desse modo, 
entendemos que, através do uso do gênero resenha crítica, o aluno terá oportunidade de desenvolver uma série de habilidades que servirão tanto para o trabalho com outros gêneros textuais como para a produção de um resumo ou para a produção de outros gêneros organizados conforme a sequência dissertativa-argumentativa ${ }^{6}$, por exemplo.

Para reforçar a ideia de que é profícuo o trabalho com gêneros em sala de aula, Kleiman apresenta um relato de experiência com alunos da $7^{\mathrm{a}} \operatorname{série}^{7}$ do ensino fundamental.

Em vez disso, os alunos foram experimentando com base nos gêneros que já conheciam e, aos poucos, foram inferindo os elementos relevantes para escrever seus textos, apoiando-se nas práticas de ler livros, recomendá-los ou criticá-los (informalmente) para um público conhecido, ouvir e ler comentários críticos de seus colegas, ler resenhas publicadas, revisar seus textos, reescrevê-los com base nos comentários dos colegas e, sobretudo, da professora, que certamente tinha em mente, para guiá-los nesse processo, o conteúdo visado. (KLEIMAN, 2007, p. 7-8)

Observa-se, no relato supracitado, que a professora foi gradativamente colocando os alunos em contato com os gêneros, levando-os a inferirem informações relevantes para a composição do seu texto. A função da professora foi essencial para o desenvolvimento da atividade, uma vez que esse pensar-agir ajudou os alunos a formularem sua opinião e juízo de valor sobre a obra, colocando-os como protagonistas da produção textual.

Diante do exposto, sugere-se ao professor criar estratégias para o trabalho com o gênero em sala de aula, como a preparação de oficinas ou de sequências didáticas, algo que seja sistemático, que envolva os elementos do gênero de maneira processual.

O uso do gênero resenha crítica é importante nas práticas sociais de linguagens, porque coloca o aluno em contato com todo o seu contexto de produção, seja considerando o espaço físico-temporal, seja considerando a relação entre os interlocutores, o propósito comunicativo, o suporte etc (BRONCKART, 2007). No ensino da resenha, o professor pode pedir que os alunos caracterizem a situação de produção, identificando elementos como autor, função social, imagem projetada do destinatário, objeto resenhado, local veiculado, momento da produção e objetivos do autor (MACHADO; LOUSADA; ABREU-TARDELLI, 2004).

Após a exposição das peculiaridades do gênero resenha crítica feita pelo professor, o aluno é convidado a pensar qual é o seu papel social ao produzir uma resenha, quem será o destinatário, em que local a resenha irá circular, qual é o objetivo, dentre outros. A ideia deste artigo é explicitar uma prática que defenda o ensino do gênero, pautada no contexto de

\footnotetext{
${ }^{6}$ Como o gênero Redação do ENEM.

${ }^{7} \mathrm{Na}$ época, as turmas eram divididas em séries. Atualmente, seria o $8^{\circ}$ ano do Ensino Fundamental.
} 
produção, para levar o aluno a refletir sobre as variadas práticas sociais presentes no seu cotidiano.

Como a resenha envolve a capacidade de síntese, de opinar e de emitir juízo de valor, trata-se de um excelente gênero para o desenvolvimento de habilidades linguísticas, textuais e discursivas. Outro fator importante é que não há produção de texto sem que haja uma leitura eficiente, pois, segundo os PCN,

O trabalho com leitura tem como finalidade a formação de leitores competentes e, consequentemente, a formação de escritores, pois a possibilidade de produzir textos eficazes tem sua origem na prática de leitura, espaço de construção da intertextualidade e fonte de referências modalizadoras. A leitura, por um lado, nos fornece a matéria-prima para a escrita: o que escrever. Por outro, contribui para a constituição de modelos: como escrever. (BRASIL, 1997, p. 40)

Em nota de rodapé, os PCN esclarecem que não se trata de formar escritores profissionais e sim pessoas com proficiência escrita. Conforme o excerto acima, a ideia de se trabalhar em sala de aula com gênero textual inicia-se com a leitura de diversos textos, pois, para a produção da resenha, o aluno precisará recorrer frequentemente ao texto como ponto de partida para compor seu processo de retextualização. O texto serve ainda como modelo de como se deve escrever, ou seja, "o gênero como instrumento para o desenvolvimento da linguagem.”. (DOLZ \& SCHNEUWLY, 2004, p.80).

\section{Metodologia}

Optamos por desenvolver este trabalho por meio da pesquisa-ação que, segundo Thiollent, constitui

[...] um tipo de pesquisa com base empírica que é concebida e realizada em estreita associação com uma ação ou com a resolução de um problema coletivo e no qual os pesquisadores e participantes representativo da situação ou do problema estão envolvidos de modo cooperativo ou participativo. (THIOLLENT, 1985, p. 14 apud GIL, 2002, p. 55)

Segundo Thiollent (1985, apud Gil, 2002, p. 56), “a pesquisa-ação geralmente supõe uma forma de ação planejada, de caráter social, educacional". Esse excerto confirma a natureza da investigação, pois visa suscitar reflexões sobre a relação ensino-aprendizagem no contexto escolar.

Para a implementação da pesquisa, utilizamos o modelo de sequência didática proposto por Dolz, Noverraz e Schnewly (2004). Segundo os autores, por meio do planejamento de atividades organizadas de maneira sistemática em torno de um gênero, é possível desenvolver 
competências linguísticas. Entende-se, então, que a sequência didática tem a finalidade de auxiliar o aluno a dominar melhor um gênero textual, permitindo-lhe escrever ou falar de acordo com a situação comunicativa. Ainda conforme os autores, a sequência didática é composta por uma situação inicial (apresentação de todo o processo que será desenvolvido), por uma produção inicial, pela aplicação de módulos de atividades e, por fim, por uma produção final.

No caso desta pesquisa, a sequência didática é composta por oito planos de aula, considerando as seguintes etapas: apresentação da situação inicial, produção inicial, atividades 1 e 2, produção intermediária, atividades 4 e 5 e a produção final. Na nossa sequência, acrescentamos uma produção intermediária, com o propósito de avaliar o aprendizado desenvolvido nas atividades 1 e 2 . Até a análise dos textos desse trabalho, nossa pesquisa encontrava-se na fase da produção intermediária.

O professor pesquisador exibiu o filme Mulher-Maravilha (2017), cuja duração é de 141 minutos, dirigido por Patty Jenkins. Após a exibição do filme, foi solicitada a produção de uma resenha crítica. A adesão a essa atividade foi significativa, pois 24 alunos de um quantitativo de 32 entregaram suas produções. Na sequência, efetuamos uma análise longitudinal das 24 resenhas críticas e uma análise mais detalhada, verticalizada, de dois textos dentre os 24 entregues, a fim de que pudéssemos refletir sobre a compreensão do gênero resenha crítica por parte dos discentes.

Escolhemos a turma de uma escola pública estadual, localizada no município de Fortaleza- Ce, pertencente a um bairro de periferia. Essa turma era composta por 20 pessoas do sexo feminino e por 12 do sexo masculino, sendo que as idades variavam entre 12 e 17 anos.

Após a leitura da produção inicial, as resenhas foram devolvidas para a turma, momento em que os alunos disseram que nunca tiveram uma aula sequer sobre a produção do gênero resenha. Nas aulas seguintes, desenvolvemos dois módulos com a finalidade de melhorar o desempenho nas próximas produções de resenhas críticas.

Para a análise dos dados, foram levados em consideração um dos aspectos adotados na metodologia proposta por Cervera (2008, p. 79) que é “o plano global mínimo (descrição técnica, resumo e avaliação)." assim como outros elementos identificadores do gênero. $\mathrm{Na}$ próxima seção, trataremos da análise das resenhas selecionadas.

\section{Análise das resenhas produzidas}

Os alunos assistiram ao filme Mulher-Maravilha (2017), sendo necessárias três aulas de 50 minutos para sua exibição. Após o término do filme, na aula seguinte, o professor solicitou 
que os estudantes fizessem uma resenha, objetivando perceber o que já sabiam a respeito do gênero.

De acordo com a metodologia de Cervera (2008), analisamos o plano global mínimo que é a apresentação do objeto (descrição técnica), o resumo e a avaliação (apreciação por meio de comentários positivos e negativos), se havia ficha técnica, se o aluno inseriu um título, se ele relacionou o filme com outras obras e se utilizou de vocabulário adequado.

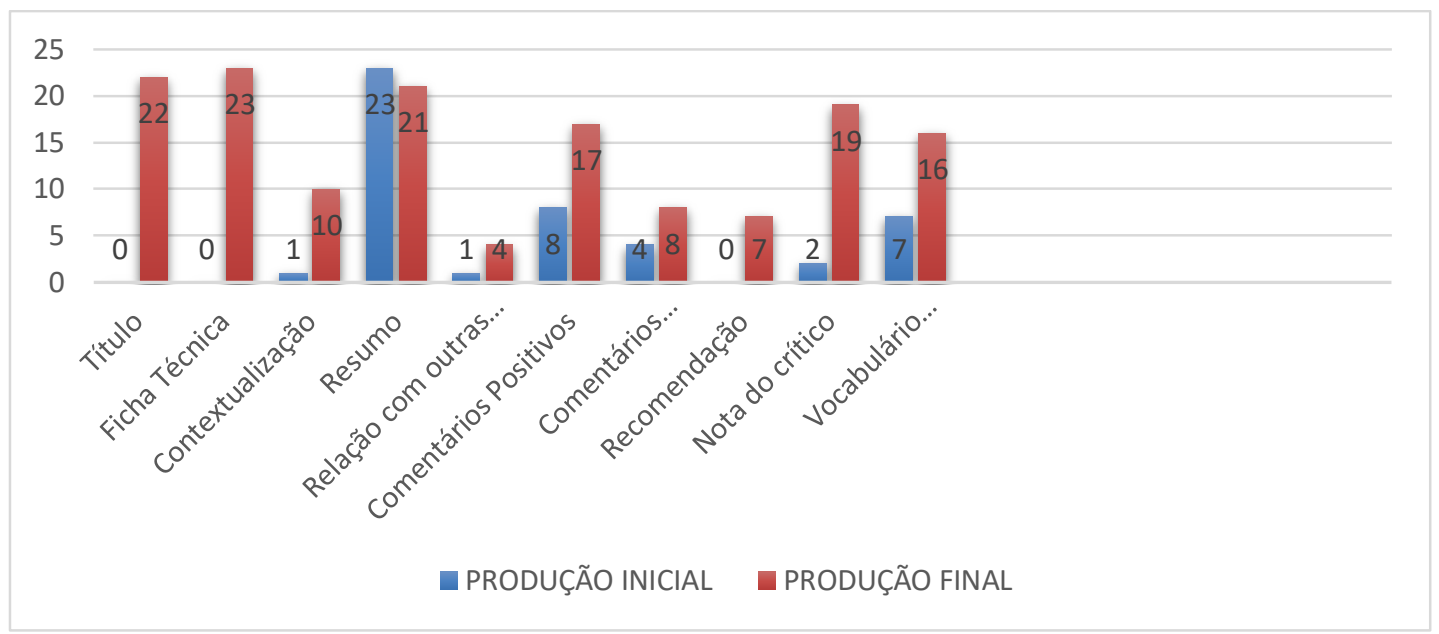

Gráfico 1 - Comparativo entre a produção inicial e a reescrita. Fonte: Elaboração dos autores, Fortaleza, 2018.

Antes de analisarmos o gráfico acima, salientamos que apresentamos nele os números em valores totais. Assim, foram recolhidas 24 produções e os quantitativos expostos no Gráfico são referentes a quantidade de alunos que em seus textos empregaram os elementos analisados. Mais adiante, ao comentarmos os resultados, além de mostrarmos os números em valores totais, apresentaremos também números percentuais para reforçar e para ilustrar, de forma clara, o quanto a turma melhorou nos aspectos avaliados.

Conforme o Gráfico 1, percebemos significativas diferenças entre a produção inicial e a produção final, após a proposição dos módulos da sequência didática. Por exemplo: em nenhuma produção inicial os alunos colocaram títulos nem se preocuparam com a ficha técnica, tampouco atentaram-se em recomendar o filme. Ao lermos as produções iniciais, notamos apenas a preocupação em resumir o filme, sendo que alguns fizeram isso até com muitos detalhes, algo que não é recorrente em resenhas.

Outro aspecto que nos chamou atenção foi a diminuição dos resumos, se compararmos a produção inicial em detrimento da produção final ${ }^{8}$. Na primeira produção, 23 dos 24 alunos

\footnotetext{
${ }^{8}$ Apesar de chamarmos a última produção escrita de produção final, vale ressaltar que esta se trata ainda da produção intermediária, ou seja, é uma reescrita prevista na sequência didática.
} 
escreveram o resumo, ao passo que, na segunda produção apenas 21 de 24 preocuparam-se com a elaboração de resumo. Talvez isso tenha acontecido pelo fato de os alunos, na reescrita, preocuparem-se mais em atender outros elementos da resenha crítica expostos nos módulos e, por essa razão, não se detiveram ao resumo, trazendo prejuízo para a satisfação plena da produção do gênero resenha crítica. Algo a ser reforçado com a continuação das atividades da sequência9.

Em relação à contextualização, na primeira produção, apenas um aluno de 24 , menos de 5\% da turma, preocupou-se em contextualizar, enquanto que, na segunda produção, 10 de 24, em torno de $41 \%$ da turma, preocuparam-se em situar o leitor. Nesse caso, contextualizar significa apresentar informações importantes sobre a personagem-título como sua origem, seu criador ou sobre o universo cinematográfico em que o filme se insere.

A apresentação de comentários positivos ou negativos foi outro fator trabalhado com a turma, pois os alunos sentem muita dificuldade em avaliar o produto e em emitir uma apreciação. Mesmo assim, o número de resenhas com comentários positivos aumentou de 8 para 17 do total de alunos. Em números percentuais, passou de 33\% para 70\%, mais do que o dobro. Também houve aumento no número de comentários negativos, que passou de 4 para 8 de 24 produções, o que em números percentuais aumenta de $16 \%$ para $33 \%$ do total de produções.

Por fim, percebemos que os alunos se preocuparam em emitir uma nota e o mais interessante é que alguns desenharam estrelinhas, simbolizando a nota do crítico em páginas da internet. Na primeira escrita, apenas 2 alunos emitiram uma nota para o filme, representando algo em torno de $8 \%$ do total de alunos. Já na reescrita, o número de resenhas com notas corresponderam a 19 de 24 , representando $79 \%$ das produções, ou seja, houve um aumento considerável desse elemento das resenhas.

A linguagem dos textos estava conforme o perfil do público leitor ${ }^{10}$. Percebemos, dessa forma, uma preocupação com um vocabulário adequado ao contexto, pois, já na primeira escrita, 7 produções mostraram-se preocupadas com isso, algo em torno de $29 \%$. Na produção final, 16 produções procuraram adequar a sua escrita de acordo com o contexto comunicativo, representando $66 \%$ do total.

\footnotetext{
${ }^{9}$ No momento da elaboração deste artigo, a sequência didática não havia se exaurido, faltando ainda dois módulos e a escrita final.

${ }^{10}$ Sugerimos aos alunos que o público-alvo seriam os fãs de filmes de super-heróis ou fãs da personagem MulherMaravilha, logo perfil do público são, de forma geral, pessoas de várias idades interessadas em conhecer a obra, porém com um grau de escolaridade básico - ensino médio.
} 
Partindo para análise focada em duas produções, os alunos serão identificados como A1 e A2 e, para uma melhor análise, faremos o recorte dos textos.

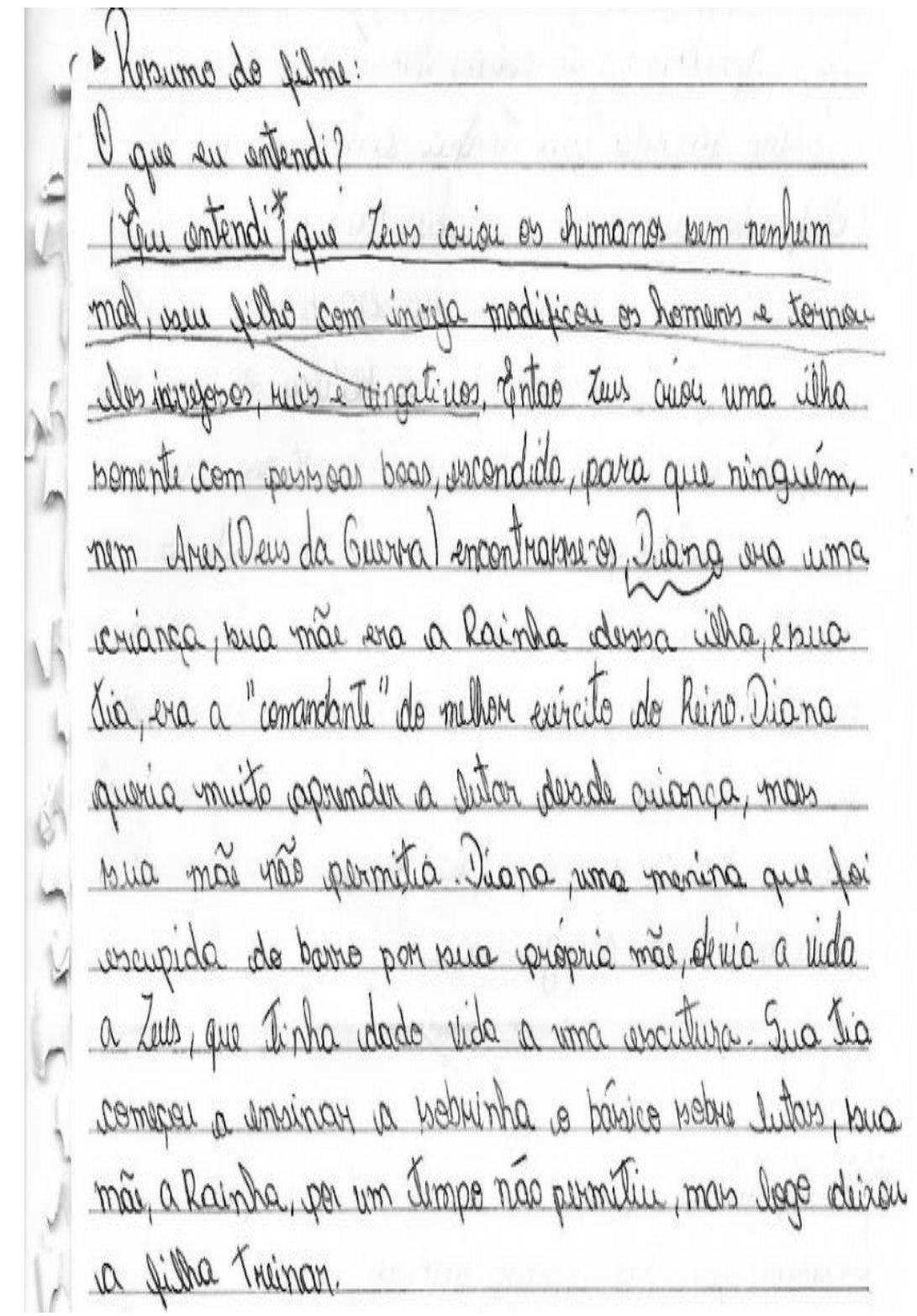

Figura 01 - Produção Inicial A1. Fonte: Dados coletados com a aplicação da pesquisa, Fortaleza, 2018.

Nessa primeira produção do aluno $\mathrm{A} 1$, a princípio, notamos que ele referiu-se à resenha como resumo do filme, não colocou título e escreveu o texto em primeira pessoa, como nota-se em "Eu entendi...". O resumo estava com um nível de detalhes muito grande, algo não recomendado para esse gênero, dada a sua função social. Vale ressaltar que este aluno escreveu duas páginas (frente e verso da folha) e seu texto tratava-se apenas de um resumo. No final do escrito, o aluno utilizou-se da palavra crítica para tentar se aproximar de uma resenha crítica, o que não conferiu ao texto o caráter crítico, peculiar à resenha crítica. 


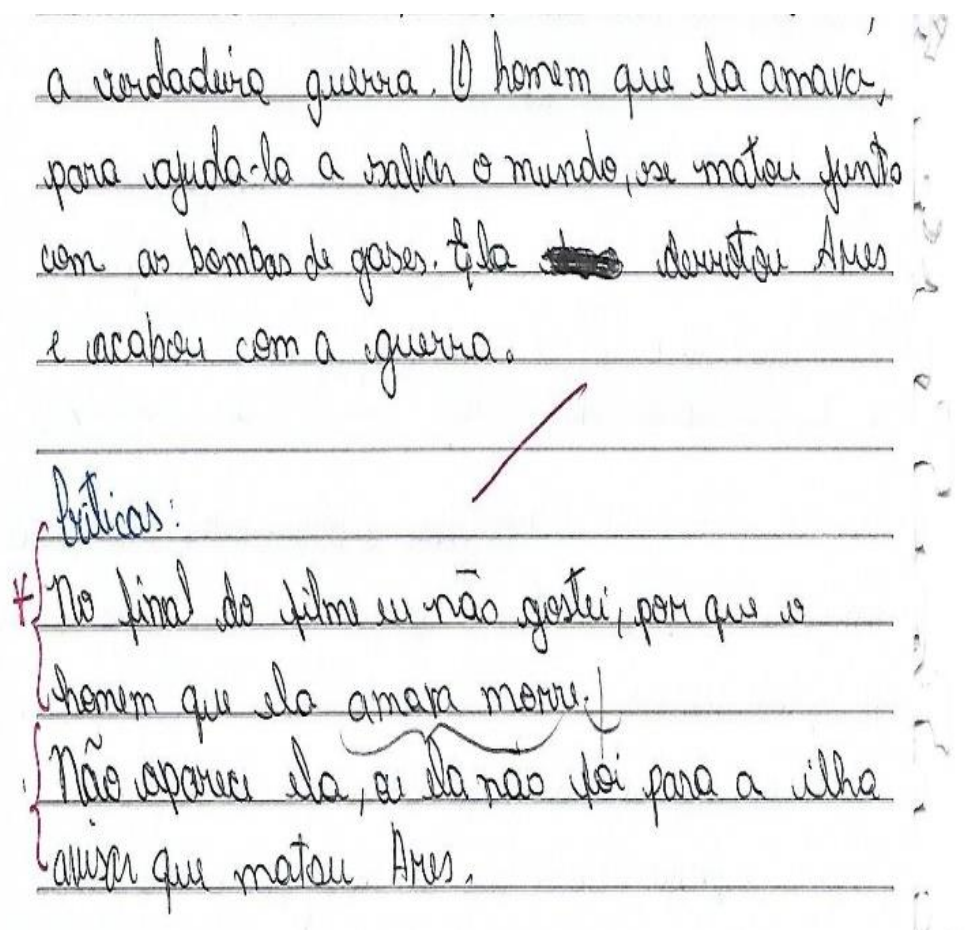

Figura 02- Produção Inicial do aluno A1 parte final. Fonte: Dados coletados com a aplicação da pesquisa, Fortaleza, 2018.

Após a produção inicial, realizamos duas atividades, antes das quais havia algumas explicações como apresentação de slides do contexto de produção, ficha técnica do filme, um pouco da história da personagem, leituras de resenhas e destaques de seus elementos. As duas primeiras atividades objetivaram extrair, de resenhas publicadas em páginas da internet especializadas e em jornais de grande circulação, elementos como a identificação do título, reconhecimento de layout, local publicado, autor da resenha, assim como levar os alunos a identificar comentários positivos e negativos e perceber como estes influenciam a nota do crítico.

Vejamos como o aluno A1 apreendeu o que foi ensinado sobre a resenha crítica, aperfeiçoando, portanto, o seu texto inicial. Destacamos o início da sua reescrita, conforme ilustra a figura 03, para confrontarmos com a produção inicial.

1) Fim da guerra:

Mulher Maravitha

(1) filme apresinta um acontecimento entre Dewsose humanos, Mitologia grega. Leus icriou" os humanos som nenturm defetto, sose filth Ares (Deus de guerra) com insya madificas os homens e tanou eles, minse vinaatives 
Figura 03 - Reescrita do aluno A1. Fonte: Dados coletados com a aplicação da pesquisa, Fortaleza, 2018.

Na produção final, o aluno procurou inserir a identificação do objeto resenha e um título, elementos ausentes na sua primeira produção. Percebemos que ele se apropriou da forma de composição do gênero resumo, pois, ao iniciar a escrita com "O filme apresenta...", houve uma tentativa de se distanciar do texto, valendo-se da terceira pessoa. Outro aspecto curioso dessa reescrita é que o aluno se preocupou em atribuir nota, em exibir a ficha técnica do filme e ainda apresentou comentários positivos como em "[...] a história emociona muito e prende a atenção do telespectador." e em "[...] o filme fica ainda mais emocionante e não decepciona.". Conforme se verifica na figura 04 .

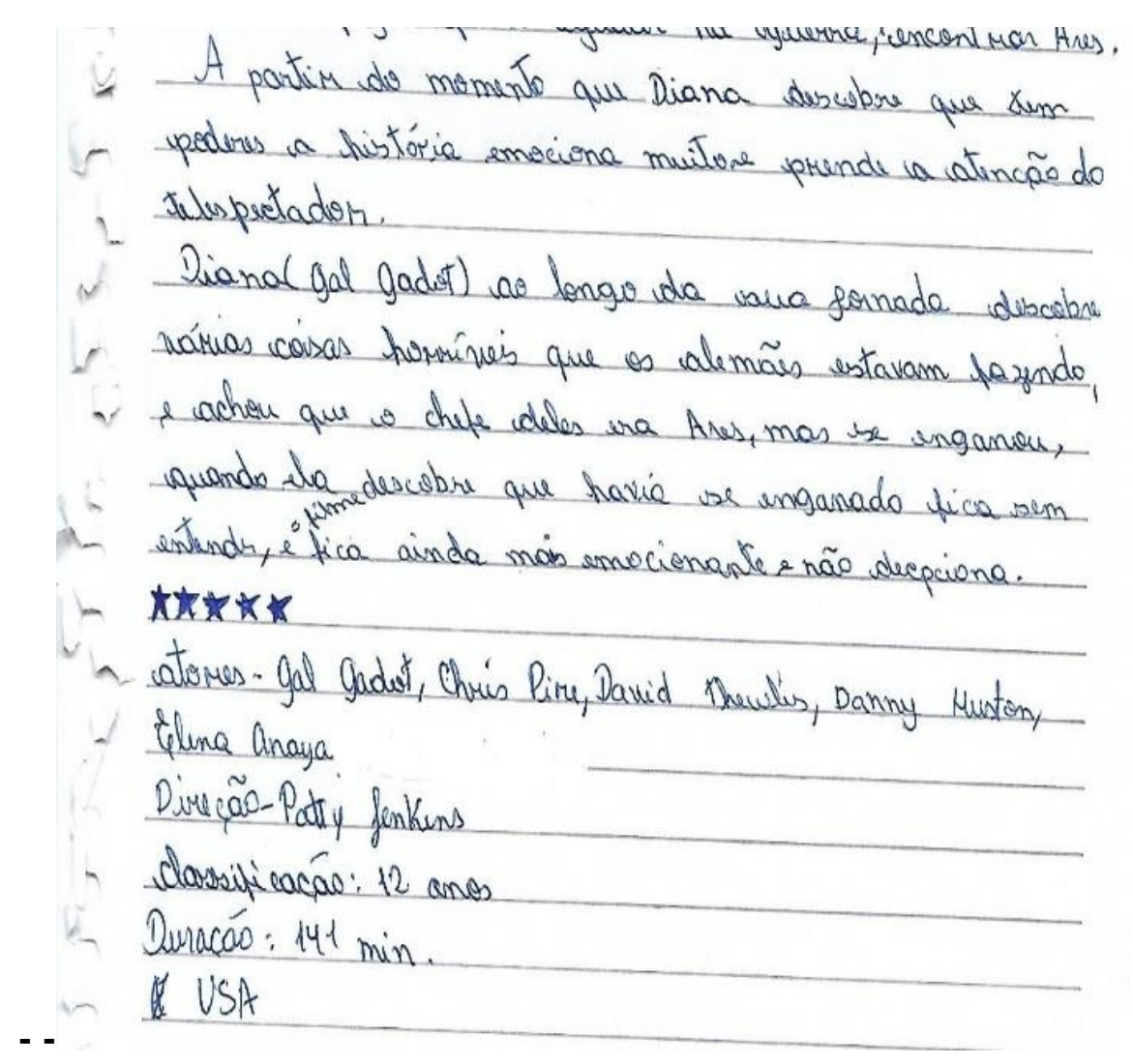

Figura 04 - Reescrita do aluno A1. Fonte: Dados coletados com a aplicação da pesquisa, Fortaleza, 2018.

Notamos um considerável avanço em relação ao primeiro texto, pois, no segundo texto, o aluno inseriu muitos outros elementos, atendeu o plano global mínimo da resenha, realizou sua apreciação, atribuiu nota e conseguiu ser mais objetivo no resumo, uma vez que seu texto ocupou apenas uma página.

Passemos, agora, para a produção inicial do aluno A2. 


\section{Eritiea do filme "Mulhor- mara witha"}

Bind, IEu vosstei bastante do filme, whei bem legal, gosti muito da atwaeas de bal. Gadot thianal elvis pine (Steve), Gostei da maravilhosa trith Sonora na varte sque eles lectam. Un das methores filme aque un fá assiste.

Adori" "mulher- mana witha" mais do sqoue deveria, mas isso nä signifiea Gue ele i perfeito. Os Visuris do espaco acabaram the thamando mais a vateneas 'do que os diáloqos e a trama muitas vezes. Nas lenas de aceä, sä vários confrontos e todos muitos Empolgantes yprinaipalmente pela postura - de "biana" A posstura el atitude da personagem fola por siso', simplemente maravilhosa, luta ppelo bem da llumanidade mesmo que estefa arriseando a sua vida, lla quur o bem de toolos e fori isso gave me for achar

Figura 05 - Produção Inicial A2. Fonte: Dados coletados com a aplicação da pesquisa, Fortaleza, 2018.

Notamos que o aluno A2 em sua produção inicial apresentou mais elementos que o aluno A1, pois trouxe a identificação do objeto resenhado e apresentou comentários positivos e negativos. O aluno apresentou as seguintes apreciações "achei bem legal" e "gostei muito da atuação...”, ambos comentários positivos e ainda conseguiu apresentar um comentário negativo como em "Os visuais do espaço me chamando mais atenção do que os diálogos e a trama muitas vezes.”. Houve muitas mudanças em relação a sua produção final, o que demonstra que o ensino de gênero deve ser contínuo e processual para uma prática formativa exitosa. Na figura a seguir, vejamos a produção final de A2. 


\section{A mulher - Heroínor}

(A mulher-maravilha foi eriada em 1941

pela be. Comies. Origem na vegenda

Guerra mundial.

naveionalismo somado a imaliposão fermi-

mina, Ela era uma semi-Leusa.

Binigido por patty fentins, oluraeāo de

141 minutos, foi de vrecorde de Bilheterria). elassifieacáo de 12 anos).

(1) fil'me "mulher - maravilha" é bem legal, muito boa va vatuareāo de Gal Gadot (Niana) e Chais Pine (vateve), muito boa a música uque eseatheram como tritha Sonora na parte vque eles lutam. Un wolos melhores foilmes uque fá assisti.

"Mulher-Marawilha" É ótimo mais do

qque deveria, porém usso nāo usignifiea que ele $i$ perfeito. (as visuais do uspaea veabaram chamando mais a vatenfä ido que os diálogos el a trama muitas vezes. Nas enas de vaçä, säo vários confrontios e todos muitos Empolgantes primeipalmente pela postura de "Wiana", A postura e a atitude da personagem fala yoer vi usó simplesmente personasem folla por vi us sinn

Figura 06 - Produção final - A2. Fonte: Dados coletados com a aplicação da pesquisa, Fortaleza, 2018.

Já na reescrita, o aluno A2 apresentou um título e, logo no início do texto, trouxe a identificação do objeto resenhado, assim como uma contextualização da personagem. Salientamos que, apesar de sua escrita apresentar as partes em períodos curtos no primeiro parágrafo, isso não atrapalhou o fluxo do texto. Notamos também o distanciamento do escritor, ao utilizar a $3^{\mathrm{a}}$ pessoa, diferenciando-se do uso da $1^{\mathrm{a}}$ pessoa no texto da produção inicial. 


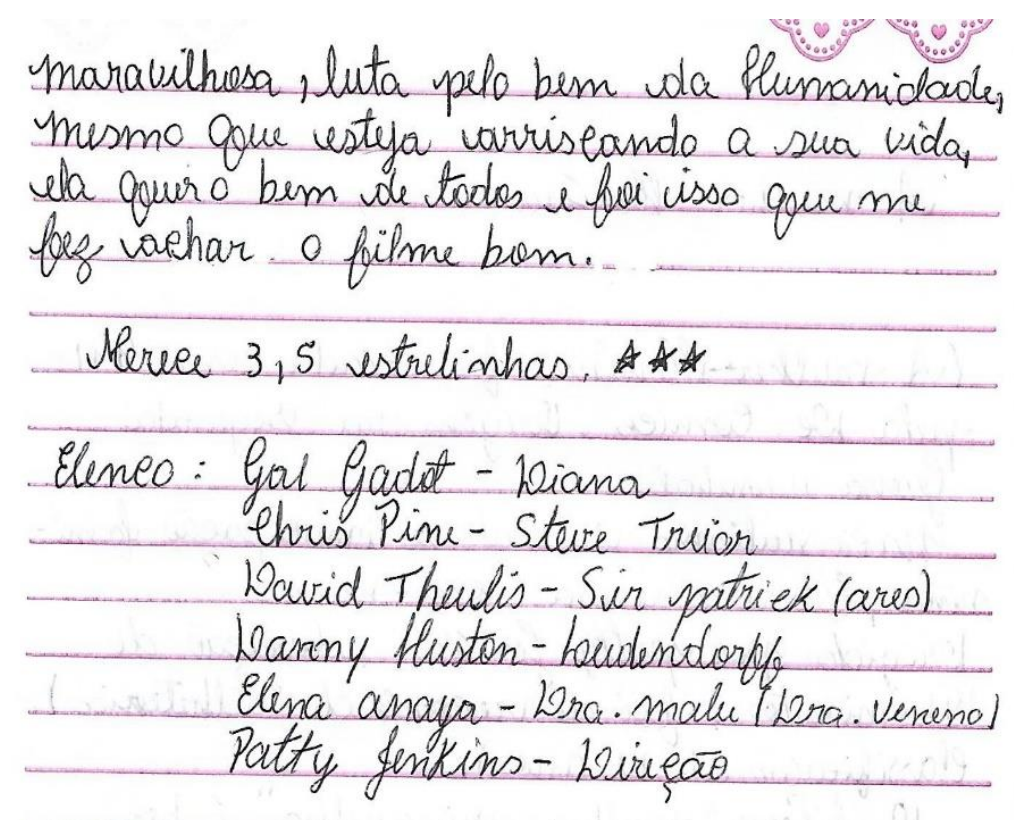

Figura 07 - Produção final A2 (parte final). Fonte: Dados coletados com a aplicação da pesquisa, Fortaleza, 2018.

Conforme vimos, o verso contém a ficha técnica e a nota do crítico. Algo muito interessante dessas duas produções analisadas é que os alunos desenharam as estrelas elemento muito comum em páginas da internet destinadas às críticas profissionais.

Percebemos, até este momento da pesquisa, como as atividades previstas nos módulos cumpriram seus objetivos, pois os alunos conseguiram desenvolver de forma mais autônoma a reescrita e foram capazes de revisar e de reavaliar seus textos. Mesmo ainda faltando concluir a sequência didática prevista, já notamos uma grande evolução em relação à apropriação do gênero, ficando clara a importância da sequência didática para o desenvolvimento das produções textuais.

\section{Considerações finais}

Para que haja um ensino eficaz, o professor precisa ter acesso às teorias que embasam o processo de ensino e de aprendizagem. Então, o docente deve repensar o seu fazer professoral e construir uma perspectiva de ensino que coloque o aluno em contato com situações reais de uso da língua. Por isso, a escola é o lugar ideal para aprendizagem, porque traz para seu ambiente diversos gêneros textuais que circulam todos os dias nas esferas sociais.

Percebemos que, ao entrar em contato com os mais diversos gêneros do discurso, o aluno passa a experimentar um processo de aprendizagem diferente, pois começa a estudar, além de elementos linguísticos, vários elementos extralinguísticos, como o contexto de 
produção, informações sobre o autor, enfim, vários outros constitutivos essenciais para a compreensão do texto.

Nesse sentido, a finalidade de se trabalhar gênero na escola se dá por meio da ideia de tornar o indivíduo capaz de fazer escolhas linguísticas e aprender a interagir nas mais diversas situações sociais, reforçando a ideia de se formar leitores e escritores proficientes.

Diante do exposto, entendemos que o gênero resenha crítica ajuda o aluno a dominar técnicas de resumo, a construir inferências, a emitir opinião e juízo de valor, ambos fundamentados no próprio texto. Percebemos, ainda, que desenvolve habilidades que ultrapassam o gênero estudado e que são transferíveis a outros.

Por fim, este artigo se coloca apenas como uma alternativa plausível sobre como aperfeiçoar as práticas de linguagens, por meio do ensino de gêneros.

\section{Referências}

BAKHTIN, M. Estética da criação verbal. $4^{\text {a }}$ Ed. São Paulo: Martins Fontes, 2003.

BAZERMAN, C. Gêneros textuais tipificação e Interação. Ângela Paiva Dionísio, Judith Chamblis Hoffnagel (orgs.). Revisão técnica Ana Regina Vieira et al. São Paulo: Cortez Editora, 2005.

BIASI-RODRIGUES, B. A abordagem dos gêneros textuais no ensino da Língua Portuguesa. In: Pontes, Antônio Luciano; Costa, Maria Aurora Rocha (Orgs). Ensino de Língua Materna na Perspectiva do Discurso. Vol. 1. 1ed.Fortaleza: Edições Demócrito Rocha, 2008.

BRASIL Ministério de Educação. Secretaria de Educação Fundamental. Parâmetros Curriculares Nacionais. $1^{o}$. e $2^{o}$. Ciclos: Língua Portuguesa. Brasília: MEC: SEF, 1997. Disponível em:< http://portal.mec.gov.br/seb/arquivos/pdf/livro01.pdf >. Acesso em 10 jul 2017.

BRONCKART, J. P. Atividade de linguagem textos e discursos por um interacionismo sociodiscursivo. $2^{\mathrm{a}}$ ed. Tradução de Anna Rachel Machado e Péricles Cunha. São Paulo: Educ, 2007.

CERVERA, M. C. da S. F. O ensino-aprendizagem do gênero resenha crítica na universidade. 2008. 179 f. Dissertação (Mestrado em Linguística). Pontifícia Universidade Católica de São Paulo, São Paulo.

DOLZ, J.; NOVERRAZ, M.; SCHNEUWLY, B. Sequências didáticas para o oral e a escrita: apresentação de um procedimento. In: DOLZ, J. \& SCHNEUWLY, B. Gêneros orais e escritos na escola. Tradução de Roxane Rojo e Glaís Sales Cordeiro. Campinas: Mercado de letras, 2004. 
DOLZ, J.; SCHNEUWLY, B. Os gêneros escolares - das práticas de linguagem aos objetos de ensino. In: Gêneros orais e escritos na escola. Tradução de Roxane Rojo e Glaís Sales Cordeiro. Campinas: Mercado de letras, 2004.

GIL, A. C. Como elaborar projetos de pesquisa. 4. ed. São Paulo: Editora Atlas, 2002.

KLEIMAN, A. B. LETRAMENTO E SUAS IMPLICAÇÕES PARA O ENSINO DE LÍNGUA MATERNA. Signo. Santa Cruz do Sul, v. 32 n 53, p. 1-25, dez, 2007.

MACHADO, A. R.; LOUSADA, E. G.; ABREU-TARDELLI, L. S. Resenha. São Paulo: Parábola Editorial, 2004.

MARCONI, M. de A.; LAKATOS, E. M. Metodologia do Trabalho Científico. 7. ed. Revista e ampliada. São Paulo: Atlas, 2012.

MARCUSCHI, L.A. Gêneros textuais: definição e funcionalidade. In: Dionísio, A.P.; Machado, A.N.; Bezerra, M.A. (orgs). Gêneros textuais e ensino. Rio de Janeiro: Lucerna, 2002. p. 19-36.

MEDEIROS, J. B. Redação Científica: a prática de fichamentos, resumos, resenhas. 12. ed. São Paulo: Atlas, 2014.

MULHER-Maravilha. Roteirista: Allan Heinberg. Direção: Patty Jenkings. Intérpretes: Gal Gadot, Chris Pine e outros. [S/l]: Warner Bros, 2017. 1 DVD (141 min), color.

PAES, F C. de O. Ensino e aprendizagem do gênero resenha de filme no $9^{\circ}$ ano do ensino fundamental. 2018. 208 f. Dissertação (Mestrado em Letras - PROFLETRAS). Universidade Federal do Ceará. Fortaleza. [Em andamento]. 